\title{
A DESCOLORAÇÃO DO COTIDIANO ASSISTENCIAL: DIMENSÕES ÉTNICO-RACIAIS EM SAÚDE MENTAL ${ }^{1}$
}

\author{
The decolorization of everyday care dimensions ethnic-racial in Mental Health
}

Lucia Cristina dos Santos Rosa ${ }^{2}$

\begin{abstract}
Resumo
O presente artigo analisa as expressões das questões étnico-raciais no cotidiano de dois centros de atenção psicossocial, um localizado na Região Nordeste e outro na Região Sudeste do Brasil. Fundamenta-se na categoria identidade de Antonio Ciampa e na teoria do cotidiano de Agnes Heller. Trata-se de uma pesquisa de natureza qualitativa, com triangulação de técnicas, com o emprego privilegiado de grupos focais e observação participante. Teve por sujeitos os usuários, os familiares e os profissionais. Os CAPS que serviram de base empírica da pesquisa conformam-se como serviços plurirracial, predominando as etnias brancas e negras, mas tal aspecto fica invisibilizado no dia a dia, tanto estatisticamente quanto no manejo do cuidado.
\end{abstract}

Palavras-chave: Etnia. Raça. Saúde mental. Diversidades.

\begin{abstract}
This article analyzes the expressions of ethnic and racial issues in the daily two psychosocial care centers, one located in the Northeast and one in southeastern Brazil. Based on the category of identity Antonio Ciampa and the theory of everyday Agnes Heller. This is a qualitative research with triangulation techniques, employing privileged focus groups and participant observation. The subject's users, family members and professionals. The CAPS that formed the basis of empirical research conform to pluriracial services, predominantly white and black ethnic groups, but this aspect is made invisible in everyday life, both statistically and in the management of care.
\end{abstract}

Keywords: Ethnicity. Race. Mental Health. Diversities.

\section{INTRODUÇÃO}

Saraceno (1994) ao analisar as variáveis sombras na saúde mental, reproduzindo seu eurocentrismo, exclui os pertencimentos étnicos raciais como atravessando o cotidiano da Saúde Mental, o que no caso brasileiro tem que ser agregado entre as informações em saúde, em função do passado histórico da sociedade

\footnotetext{
${ }^{1}$ Este trabalho é parte do relatório de pesquisa CAPS: um serviço de classe, gênero e etnia, desenvolvido como atividade do estágio pós doutoral em saúde coletiva realizado na UNICAMP, no período de agosto de 2011 a dezembro de 2012.

2 Docente do Departamento de Serviço Social da UFPI. Doutora em Serviço Social pela UFRJ. Pós

Doutora em Saúde Coletiva pela UNICAMP. Telefone: 86 3215-5784. E-mail: luciacsrosa@gmail.com. Serv. Soc. \& Saúde, Campinas, SP v. 13, n. 1 (17) p. 9-28 jan./jun. 2014 ISSN 1676-6806
} 
brasileira em que o poder se cristalizou como "macho, branco e, de preferência heterossexual" (SAFFIOTI, 2004, p. 27). Ademais, apesar do princípio da universalização postulado pela Constituição Federal de 1988, os principais usuários do Sistema Único de Saúde - SUS constituíram-se, historicamente, de segmentos da população pobre, como explicita Barata (2008). Neste segmento, segundo a mesma autora, a população negra está representada em 51,9\%, acompanhando as desigualdades que se perpetuaram no País. Em sintonia com tal aspecto, entre as conquistas dos movimentos negros está exatamente a inclusão do quesito cor nos formulários do SUS (SÃO PAULO, 2009) para detectar a distribuição desigual das enfermidades e agravos em saúde entre os diferentes segmentos que compõem a população brasileira. Tal inclusão procura dar visibilidade à realidade em saúde da população negra, comumente negligenciada ou ignorada em suas particularidades.

A expressão materializada da invisibilidade das especificidades da população negra se reproduz em todos os cenários, inclusive na produção acadêmica em Saúde Mental, com parcos textos e pesquisas relacionadas a este grupo. Em pesquisa realizada eletronicamente na base de dados BIREME-Biblioteca Virtual em Saúde, a qual abrange como base de dados a Lilacs, o Medline e o Scielo (acessado em 28/06/2014) empregando-se por descritores as categorias étnico-racial e saúde mental, nenhum artigo em português foi localizado.

O emprego dos descritores saúde mental, mulher, homem, gênero resultou em 20 textos completos, nenhum associado ao segmento negro da população, apenas um remetido à população indígena.

No país, a Etnopsiquiatria é que tem explorado as dimensões étnicas na Saúde Mental, tendo por principais representantes a Escola Psiquiátrica Pernambucana, iniciada por Ulisses Pernambucano de Melo Sobrinho, em Recife, na década de 1920 (COELHO FILHO, 1977), e desenvolvida pela Antropologia afro-pernambucana, inaugurada por René Ribeiro, que analisa as associações entre manifestações religiosas (transes) e transtorno mental, tendo como principais autores contemporâneos, Lins (1992) e Fonseca (1999). No mesmo sentido, na Bahia tem sido recuperado o legado deixado por Rubem de Pinho (CONCEIÇÃO, NERY e PINHO, 2002).

O viés culturalista tem persistido e prevalecido, sobretudo a partir da análise da atenção à saúde oferecida pelos terreiros, a exemplo de Alves e Seminotti (2009). Tal fato está em sintonia com: a) os avanços do movimento negro que, em tempos mais recentes, conforme avalia D'Adesky (2001), busca afirmar a identidade afro-brasileira, Serv. Soc. \& Saúde, Campinas, SP v. 13, n. 1 (17) p. 9-28 jan./jun. 2014 ISSN 1676-6806 
combatendo as desigualdades sociais e toda forma de discriminação étnico-racial e b) com as conquistas em torno das políticas envolvendo a igualdade racial, impressa na Política Nacional de Saúde Integral da População Negra (BRASIL, 2007) bem como no Estatuto da Igualdade Racial (BRASIL, 2011a).

$\mathrm{Na}$ perspectiva de estudar as identidades a partir de marcadores como classe social, gênero e etnias observou-se a invisibilidade que contorna o tema étnico racial na área da Saúde Mental. Tal lacuna motivou indagações em torno das seguintes questões: Como as diferenças étnico-raciais são enfrentadas no cotidiano dos Centros de Atenção Psicossocial (CAPS)? Como se manifestam as identidades étnico-raciais de profissionais, usuários e familiares cuidadores no cotidiano assistencial? O estudo teve por objetivo analisar as expressões das questões étnico-raciais no cotidiano assistencial em Saúde Mental.

Com este estudo espera-se oferecer um balanço da produção relacionada às questões étnico-raciais na Saúde Mental, bem como dar maior visibilidade a tal identidade e às peculiaridades a ela inerentes no dia a dia do provimento de cuidados em Centros de Atenção Psicossocial.

\section{Metodologia}

A pesquisa de natureza exploratória centrou-se nas manifestações das questões étnico-raciais na Saúde Mental buscando maior familiaridade com o assunto abordado (GIL, 1999). Baseou-se na abordagem qualitativa, centrada nos processos sociais e nas interpretações que os profissionais, familiares e usuários constroem parametrados por suas vivências e diferentes inserções sociais (MINAYO, 1996), condensados no que sentem, pensam e nas suas interações cotidianas.

Constituíram sujeitos da pesquisa os trabalhadores, profissionais de nível superior e médio, usuários e familiares-cuidadores de dois Centros de Atenção Psicossocial (CAPS), localizados em duas regiões distintas do País, um na Região Sudeste, na modalidade CAPS III, aberto 24 horas por dia, todos os dias da semana, atendendo a urgências e emergências psiquiátricas, incluindo leitos psiquiátricos. E, outro na Região Nordeste, tipo CAPS II, que funciona de 08:00 as 17:00 horas, de segunda a sexta feira. O primeiro situado em região vulnerável da cidade e outro em área considerada nobre, mas permeado de todas as contradições do espaço urbano 
brasileiro, contudo prevalecendo entre seus usuários as pessoas de baixa renda. $\mathrm{O}$ primeiro será denominado, no decorrer do texto, como CAPS Sudeste e o outro CAPS Nordeste.

A pergunta sobre a identidade étnico-racial persistiu de maneira livre em todos os momentos e instrumentos de pesquisa, ou seja, não houve uma categorização apresentada à priori, possibilitando aos sujeitos uma autoclassificação a partir de seus próprios referenciais.

Vale lembrar que no Brasil há duas tendências classificatórias dominantes em termos étnico-raciais: a do Instituto Brasileiro de Geografia e Estatística (IBGE, 2011) com cinco categorias: branca, preta, amarela, parda e indígena; e a proposta pelo movimento negro, que postula; com base no modelo americano, duas categorias, branca e negra, essa última incluindo os pardos, mestiços, dentre outros grupos não brancos.

Alguns segmentos disputam pela hegemonia de um destes sistemas classificatórios, "outros continuam a celebrar as virtudes da 'mistura', tanto de genes quanto de culturas. Outros ainda apoiam uma combinação dessas ideias e invocam-nas de acordo com a situação" (FRY, 2005, p. 210).

Na avaliação de Bastos e Faerstein (2012) no Brasil é mais comum o emprego do termo "cor", tendo em vista as peculiaridades do "cálculo racial brasileiro" (p. 81), que ganha conotações singulares em função das circunstâncias, classificadas de um lado, em áreas duras (mercado de trabalho e relações amorosas) e áreas moles (abarcando esferas do lazer e demais relações informais) e, de outra maneira envolvendo a posição socioeconômica da pessoa.

O período da coleta de informações ocorreu de agosto de 2011 a julho de 2012, tendo por principais instrumentos o grupo focal com trabalhadores e usuários e, a análise documental, com base nos documentos de primeira mão (GIL, 1999), principalmente, mapas estatísticos e relatórios e, a observação participante das rotinas do serviço, haja vista que muitos aspectos das questões étnico-raciais persistem como ocultas na sociedade brasileira, pois como informa Figueroa (2004) a partir da obra de Florestan Fernandes, está é uma sociedade que tem preconceito a ter preconceitos.

Os grupos focais tiveram dois momentos distintos. $\mathrm{O}$ primeiro teve como base um roteiro de perguntas e ângulos de observação bastante flexível visando incrementar a análise e o debate entre os participantes, contornado pelas questões norteadoras da pesquisa. Em um segundo momento, uma síntese foi produzida e apresentada ao grupo, 
na perspectiva de oferecer uma devolutiva para conhecimento da direção da análise e validação do material produzido.

A análise de conteúdo (BARDIN,1979), na sua vertente temática foi adotada para tratamento das informações. Mas, a exposição das temáticas foi organizada na forma de narrativa (CAMPOS, BACCARI, 2011), que conforma uma sequência que propicia sentidos aos fatos narrados, com eixos melhor explicitados (os temas) para expor o material que se apresentou no decorrer da pesquisa de maneira dispersa, fragmentada e aparentemente caótica. Três eixos temáticos contornaram a organização das narrativas: a) expressões epidemiológicas e sociodemográficas das questões étnicoraciais; b) discriminações raciais como preponderante nas expressões das questões étnico raciais; c) as expressões positivas das dimensões étnico-raciais, a estética negra em destaque.

O projeto de pesquisa foi aprovado pelo Comitê de Ética da Faculdade de Ciências Médicas da Universidade Estadual de Campinas, recebendo Parecer CEP: $\mathrm{n}^{\circ}$ 799/2011, sob CAEE: 0717.0.146.000-11. Para efeitos do trabalho de campo na Região Nordeste foi aprovado pelo Comitê de Ética do Instituto Camillo Filho, sob protocolo $\mathrm{n}^{\mathrm{o}}$ 438/11 e CAEE 0063.0.044.000-11.

\section{Questões étnico-raciais na sociedade brasileira e na Saúde Mental}

Ferreira Neto (1997) informa que a evidenciação da humanidade do outro se inicia com a dominação do homem branco e europeu, no processo de consolidação e expansão do capital no plano mundial, sobretudo entre os séculos XV e XVI, como desdobramento do processo capitalista que fomenta a navegação, na perspectiva da expansão comercial da Europa Ocidental, que permite o contato com outros povos e etnias.

Desde então, o outro é apreendido de maneira etnocentrada no homem branco europeu, guiado pelos valores religiosos cristãos, sobretudo sob a hegemonia da Igreja Católica que impunha uma visão dual de uma humanidade dividida, de um lado os cristãos e de outro, pagãos e gentios, sendo os primeiros associados com a civilização, a racionalidade, a virtude e a graça divina enquanto os segundos foram identificados como povos sem história e associados à barbárie, irracionalidade, ferocidade e crueldade (FERREIRA NETO, 1997). 
Em suma, uma parte dos seres humanos era considerada parte representativa da humanidade em geral, simbolizada no homem europeu, branco e burguês, considerada membro de uma cultura civilizada. A outra parte era remetida a uma infra humanidade, excluída do contrato social típico da sociedade moderna, equiparada ao estado da natureza, ao estado animal, consequentemente remetida a uma determinada raça, considerada inferior.

Há registros de que academicamente era comum a confusão entre etnia e raça, mas a maioria dos autores passa em tempos mais recentes a distinguir um conceito do outro. O conceito de raça tem por base a dimensão biológica/morfológica e fenotípica, relacionada à aparência física (cor da pele, tipo de cabelo).

Por sua vez, o conceito de etnia é remetido às dimensões sócio culturais, assumido mais recentemente como parte do processo de reconhecimento do outro como igual, parte de uma mesma humanidade, mas, preservado na sua diferença, na sua diversidade cultural, sendo paulatinamente distanciado das matrizes cristãs, eivadas de juízos de valor. Logo, ocorreu todo um processo sociohistórico que avalia o outro a partir do olhar e valor do homem branco colonizador europeu que gradualmente se modifica, na perspectiva de olhar o outro a partir de seus próprios referenciais, o que ganha força com a emergência da etno-história (FERREIRA NETO, 1997).

Etnia, portanto, para além do dado biológico é sempre relacional, um constructo social, que remete a uma mentalidade dominante eficaz que socialmente produziu, manteve, reproduziu e metamorfoseou diferenças em desigualdades e privilégios a partir do contato do homem branco com outros povos/etnias, a partir do processo de colonização. Permeia as formas históricas e socialmente construídas para classificar e identificar pessoas, que comumente se transformam em hierarquias, traduzindo-se em desigualdades sociais. Caracteriza uma lógica interna em cada sociedade, comandando as ações dos seres humanos no mundo (CARVALHO, 2009).

As questões étnicas no contexto brasileiro estiveram relacionadas inicialmente às questões do índio. A discussão das particularidades da população negra no Brasil vai emergir em seguida, mas, as questões envolvendo os segmentos indígenas e negros serão exploradas academicamente como um tema exótico, excêntrico, relacionado inicialmente ao romance e depois ao folclore.

A partir dos anos de 1950 é que ganham densidade sociológica e antropológica, a partir das pesquisas financiadas pela UNESCO. 
A maioria dos autores brasileiros ao discutir as questões étnicas estabeleceu historicamente uma comparação com os países de primeiro mundo, sobretudo com a realidade americana, apresentando as peculiaridades das manifestações destas dimensões das relações sociais em cada contexto.

Segundo Carvalho (2009), a classificação étnico-racial nos Estados Unidos tem por principal elemento regras de descendência. Como destacam Bastos e Faerstein (2012) a ancestralidade, explicita na "regra de uma gota" (p. 82) - alusão a uma gota de sangue negro - fundamenta a perspectiva analítica americana. Sócio culturalmente a questão étnico-racial na América do Norte é enfrentada inicialmente através de uma clara demarcação entre brancos e negros, marcada pela intensa segregação e discriminação racial para uso de determinados lugares públicos, em que o conflito inter étnico se configurava bem evidenciado, de maneira confrontativa.

As expressões da questão étnico-racial nos países latino americano apresentam especificidades em pelo menos dois sentidos. A forma distinta com que negros e indígenas foram tratados e enfrentaram a questão da escravidão. E, a questão das particularidades da questão do negro na sociedade brasileira que, a partir da obra de Gilberto Freire, principalmente Casa grande e Senzala (2006), passa inicialmente a ser visualizada a partir do mito da "democracia racial", que camufla as questões raciais sob o manto de uma relação inter étnica harmoniosa e pacífica, posto como subjacente uma relação cordata.

No primeiro sentido, os índios por viver e lutar em território de seu domínio tiveram maior condição de resistir à escravidão, preservando sua identidade nativa. Por sua vez, os negros, com suas diferentes tribos e tradições, foram retirados à força de seu continente de origem, a África e transportados para uma nova nação, em que nada dominavam. Tiveram maiores dificuldades em se contrapor à escravidão, muito embora, tenham enfrentado várias batalhas e em algumas delas foram relativamente bem sucedidos, a exemplo da experiência do Quilombo de Palmares.

Vigoya (2005) registra que nos países latino americano os segmentos indígenas e negros ocuparam posições bem diferentes na estrutura de alteridade. Os primeiros tenderam a conquistar reconhecimento por sua etnicidade, "es decir de significantes culturales" (p. 494). Por sua vez, os segmentos afrodescendentes, apesar de numericamente superior à população indígena, no contexto brasileiro, em que a 
definição de etnicidade se fundamenta em uma classificação fluída e variável é suportada em dois aspectos principais, constituído pelas seguintes características:

[...] a aparência (fenótipo, envolvendo a cor da pele e o tipo de cabelo), na ascendência ou origem, mas principalmente no status socioeconômico da pessoa e de sua família, seguidos de outros aspectos decorrentes deste último como nível de escolaridade e espaço de moradia, quer urbano e rural quer centro ou periferia (CARVALHO, 2009, p. 313).

Dessa maneira, no Brasil, para além da descendência, ganham destaque, além dos aspectos físicos da pessoa, a posição que a mesma ocupa na estrutura de classes, o status socioeconômico, que tem um peso considerável na avaliação de sua posição e identidade social. Vale lembrar que numa sociedade que teve suas origens cravadas no sistema escravocrata, em que a população não branca, sobretudo negra, foi a principal vítima para a qual o Estado não saldou sua dívida social, as desigualdades sociais se manifestam sobremodo neste segmento, de maneira conjugada, comumente associando diversos estigmas, permeados pelas origens de classe e étnicas.

No texto da Política Nacional da Saúde Integral da População Negra (BRASIL, 2007) são apresentados dados do Censo de 2000 que comprovam que os negros preponderam negativamente na maioria das taxas relacionadas às várias políticas públicas, em comparação a outras etnias, sobretudo à branca, compondo: 18,2 entre os analfabetos; $65 \%$ entre os pobres e $70 \%$ entre os extremamente pobres enquanto os brancos representam $35 \%$ dos pobres e $30 \%$ dos extremamente pobres. Sem apresentar dados estatísticos é informado ainda que é consenso entre os pesquisadores que a população negra prevalece nos dados relacionados a doenças e agravos. Promovendo-se um recorte, tendo em vista o objeto do presente estudo, os negros preponderam naquelas enfermidades relacionadas às "adquiridas em condições desfavoráveis" (p. 28), destacando-se a vitimização do segmento negro entre as mortes violentas, o sofrimento psíquico, estresse, depressão e consumo nocivo de álcool e outras drogas (p. 29).

O relatório final da III Conferência Nacional de Saúde Mental (BRASIL, 2001) nas diretrizes gerais sobre "Medidas de apoio e de atenção a grupos específicos" (p. 124) destaca a importância de recortes de gênero, raça e etnia na elaboração, implantação e execução de políticas públicas no campo, merecendo destaque o item 441 - que enfatiza o desenvolvimento "de estudos e pesquisas que investiguem o impacto na Saúde Mental da população negra e da população indígena” (BRASIL, 2002, p. 125). 
O relatório final da IV Conferência Nacional de Saúde Mental Intersetorial, (BRASIL, 2011) incorpora o subitem 2.9 no eixo II "Garantia do acesso universal em Saúde Mental: enfrentamento da desigualdade e iniquidades em relação à raça/etnia, gênero, orientação sexual, identidade de gênero, grupos geracionais, população em situação de rua, em privação de liberdade" (p. 99). Trata da importância do enfrentamento do tema das diversidades na discussão da Saúde Mental, reforçando a necessidade do fortalecimento das políticas de promoção da igualdade, da necessidade de assegurar meios, acolher as questões das diferentes identidades bem como a importância de se intensificar o combate das desigualdades, os estigmas e estereótipos, voltando-se para a construção de uma nova cultura e para a produção de serviços que respeitem as particularidades dos diversos segmentos sociais.

Em síntese, a conquista dos vários movimentos sociais forja a inclusão na agenda governamental de diversas demandas redundando no reconhecimento estatal das particularidades dos diversos segmentos sociais, da luta pelo combate às iniquidades sociais e formulação de políticas públicas específicas.

O aparente baixo impacto no cotidiano assistencial dos centros de atenção psicossocial (CAPS) e na produção acadêmica em Saúde Mental dos avanços consignados pelos movimentos sociais traz o risco de reforçar a naturalização das identidades étnico-raciais, reiterando uma visão ultra generalizante do cotidiano como destaca Heller (1989).

Analisar e problematizar tais questões pode trazer subsídios para um novo adensamento do cotidiano e revigoramento de outras dimensões, ainda pouco exploradas no cerne do processo reformista em Saúde Mental, sobretudo circunscrito ao lugar e situação dos distintos grupos étnicos.

\section{Manifestações etnico-raciais nos CAPS - a partir das informações epidemiológicas e sociodemográficas}

Observou-se que as dimensões étnico-raciais comumente são silenciadas, permanecendo invisíveis no cotidiano de cuidados dos dois serviços pesquisados, necessitando ser invocada pelo pesquisador. Todavia, alguns dados sociodemográficos e epidemiológicos podem informar dimensões fundamentais que contorna a identidades dos trabalhadores e usuários dos equipamentos. 
A partir de um questionário foi perguntado a etnia auto referenciada de cada profissional.

No CAPS Sudeste observou-se que dos 48 profissionais que compõem sua equipe, em termos étnicos figura a seguinte auto referência: 35,5\% brancos; $28,9 \%$ pardos e $20 \%$ negros.

A maioria dos profissionais pardos e negros exerce atividade na área de enfermagem, sobretudo sendo técnicos, de nível médio e auxiliares de enfermagem, atividades que exigem menor qualificação profissional/escolaridade. Tal fato espelha as desigualdades da sociedade brasileira, haja vista os poucos profissionais negros com nível superior não exercerem cargos do seu nível de ensino correspondente ou mesmo haver poucos negros nesta etapa de escolaridade.

Dos 52 trabalhadores do CAPS Nordeste, 51,8\% se classificou como branco; $33 \%$ se classificou como pardo, 7,6\% como negro e o mesmo percentual como moreno, em uma alusão a uma classificação mais flexível e plural. Pessoas não brancas foram mais comuns na equipe de nível superior desta Região, muito embora numericamente ainda minoritária.

Nas informações epidemiológicas do CAPS Sudeste, embora haja registro do quesito cor nos formulários que constam nos arquivos do computador do serviço, esse dado (cor, etnia/raça) não estava processado, em 2011, como uma informação em saúde acerca de seus usuários, tendo a pesquisadora que coletar a informação diretamente nos registros digitais do equipamento, o que pode sinalizar que, na Saúde Mental, ainda não se constituiu uma cultura de valorizar tal informação, pois apenas as informações sexo e faixa etária estavam processadas estatisticamente nos documentos do serviço, sinalizando também que a identidade de gênero e etária é que tem primazia, ignorandose as demais.

Em relação aos familiares-cuidadores, pessoas responsáveis pela pessoa com transtorno mental diante dos serviços de saúde mental, inexistem informações sócio demográficas, mas, observou-se, nas reuniões de familiares, a predominância do segmento negro.

Conceição, Nery e Pinho (2002) atestam que modelos e lugares distintos de tratamento são destinados a públicos-alvo específicos, em função de sua origem de classe e também étnica/raça, "cor".

Avaliando as estatísticas de um Serviço de Saúde Mental na Bahia os autores constatam que a população negra predominava nos serviços públicos de Saúde Mental: Serv. Soc. \& Saúde, Campinas, SP v. 13, n. 1 (17) p. 9-28 jan.jun. 2014 ISSN 1676-6806 
"negros e mulatos são quase 60\% dos deprimidos do Hospital Professor Edgar Santos, que representam os consulentes mais pobres. Os negros são menos numerosos na clínica particular, onde os brancos predominam" (CONCEIÇÃO, NERY, PINHO, 2002, p. 73).

Dos 367 usuários cadastrados no sistema informacional do CAPS Sudeste, observou-se que 50,4\% era de cor branca; 39\% parda; $10 \%$ negra; e 0,6\% não constava. Portanto, há o predomínio da população branca. Mas se somarmos o número da população parda e negra, como recomenda o movimento negro, bem como o Estatuto da Igualdade Racial (BRASIL, 2010a), totaliza-se 49\% de população negra, ou seja, a diferença numérica entre brancos e negros figura estatisticamente insignificante, com empate técnico. Todavia, é um dado importante para se considerar na implementação das ações em Saúde Mental, pelas várias barreiras que o segmento negro enfrentou e vem enfrentando em uma sociedade forjada sob o mito da igualdade racial e pelas desigualdades sociais mais intensificadas e visibilizadas neste grupo.

$\mathrm{Na}$ estatística de usuários ativos, fornecida pelo Serviço de Arquivo Médico do CAPS do Nordeste, em 11 de julho de 2012, referente ao período de 4 de abril a 31 de agosto de 2012, predominava o segmento pardo da população, representado em $62,5 \%$. A cor branca representava $8,75 \%$ e as preta e amarela, igualmente, estavam representadas em 5,625\%. Mesmo com uma representação majoritária do segmento não branco, a questão étnica não figurou como tema das reuniões nem das indagações dos profissionais no dia a dia assistencial.

Apesar do reconhecimento da diversidade étnica no interior do dispositivo, por alguns profissionais durante os grupos focais de ambos os CAPS, as demandas dela inerentes pareceram pontuais, localizadas em algumas identidades. Tal fato pode ser explicado pela própria dificuldade dos profissionais em lidar com a questão, pois, além do respeito que permeia e deve permear a relação deles para com os usuários, foi informado que o profissional tem que saber o momento certo de trazer a questão à tona, como esclareceu um deles, "[...] a gente precisa ter essa, também essa, esse discernimento, assim. De quando entrar, quando não".

Especulativamente, o usuário também podia não tocar no assunto por ter dúvidas de qual seria a reação do profissional, figurando um jogo de esconde-esconde, buscando talvez naturalizar algo que parecia ser incômodo, mas não emergia porque um ficava esperando do outro. Consequentemente, as expressões étnico raciais que perpassavam as relações de cuidado tendiam ao silenciamento. 


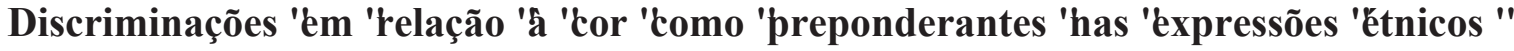 raciais dos CAPS}

Como constatam Campos e Baccari (2011) os técnicos e auxiliares de enfermagem em um Centro de Atenção Psicossocial manifestam uma intensidade significativa de sofrimento no processo de trabalho, se sentindo desvalorizados no trabalho em equipe, pois as diferenças de escolaridade e posição social se reproduzem internamente entre os trabalhadores de saúde, no cotidiano assistencial, haja vista que são os profissionais de nível superior que comumente comandam o processo de tomada de decisões, como atestam Rosa e Campos (2013).

Observando-se o processo de trabalho e possíveis expressões do racismo institucional, nos equipamentos que serviram de base empírica da pesquisa, constatou-se que o racismo ocorre às avessas, perpetrado por alguns usuários, no geral, em contexto de agudização de seu quadro clínico, para com os técnicos e auxiliares de enfermagem, sobretudo os negros, barrados em suas intervenções em saúde (BASTOS; FAERSTEIN, 2012). Por exemplo, alguns são impedidos de aplicar injeção, tocar no usuário. Ilustrativamente, uma determinada usuária se negava a aceitar tal procedimento "de um macaco", assim se referindo ao profissional por ser negro.

Um profissional comentou que a esposa do colega de trabalho, negro, estando grávida, teria sido abordado por um usuário mais ou menos da seguinte maneira: vai ser pai de um macaquinho?

O que mais chamava a atenção na primeira discriminação citada é que se poderia classificar a usuária entre os segmentos não brancos. Ainda, sendo mulher e como pessoa com transtorno mental, certamente sofria discriminações, sendo passível de ser alvo dela, em decorrência de uma ou outra identidade e nas várias circunstâncias da vida. Era assujeitada ao mesmo tempo em que era sujeito de discriminações. Tal fato denota a complexidade que contorna a discriminação, constituindo um fenômeno dinâmico (BASTOS, FAERSTEIN, 2012), em que as vítimas podem mudar de posição, denotando que incorporam muitos valores sociais do contexto em que se inserem.

Paulo Freire (1987) no livro Pedagogia do Oprimido ao analisar o processo de libertação deste ator social, analisava que em um primeiro momento havia uma identificação do oprimido com o seu opressor, no caso, a ideologia do branqueamento, o racismo, predominante na sociedade brasileira.

Serv. Soc. \& Saúde, Campinas, SP v. 13, n. 1 (17) p.9-28 jan./jun. 2014 ISSN 1676-6806 
Os profissionais de Saúde Mental, comumente são afetados pelo preconceito por trabalharem com "loucos", e, como observado, ficam expostos a outros tipos de discriminações, nas "áreas duras", isto é, no mercado de trabalho.

Todavia, como informou uma profissional negra, ela se sentia muito mais incomodada quando a violência simbólica ocorria entre os próprios usuários, quando um deles se encontrava em desvantagem, sem poder manejá-la de igual para igual. Claro que isso é, também, gerador de sofrimento para o profissional.

Quando ocorria algum episódio de discriminação do usuário para com o profissional negro os demais trabalhadores, comumente, se solidarizavam com o colega, mas, não pautavam a questão nas reuniões de equipe ou de supervisão, nem mesmo o trabalhador vitimizado. Um dos trabalhadores, alvo da discriminação, informou que adotava como estratégia de enfrentamento, desconstruir o ocorrido na cena e no cenário de sua ocorrência. De um modo geral, também se observou como estratégia a evitação, ou seja, não tocar no assunto ou o esquivar-se da abordagem da pesquisadora. Ou, ainda, tratar da questão de maneira muito genérica, como sintetizava um trabalhador, "a questão, conspira". Expressão que denota a insatisfação e o risco do profissional sair de seu lugar e arriscar enfrentá-la no plano pessoal.

Mas, como o pessoal é político, sem politizar a questão, como algo do coletivo, parte do processo de trabalho em equipe, dificilmente poderá potencializar outras relações entre profissionais e usuários, obstaculizando a construção de estratégias de enfrentamento mais potentes e empoderadoras.

\section{A expressão positiva da dimensão étnico-racial: a estética negra em destaque}

Duas vezes por semana, duas técnicas de enfermagem coordenavam o Salão de Beleza do CAPS da Região Sudeste

Foi reconhecido que o principal público demandante era de pessoas negras, e que uma demanda constante era por alisamento de cabelo.

Durante a realização do grupo focal foi reconhecido que havia pouca diversificação de ofertas de serviços de beleza, havendo no geral o atendimento ao pedido de alisamentos de cabelos, sem questionamento acerca da representação que subjazia à tal demanda. 
A discussão gerada em torno da questão culminou em ações propositivas em torno de novas ofertas, afirmativas em relação à identidade negra.

Como esclarece Ciampa (1998), a identidade é processual, metamorfose, representando a pessoa e engendrando-a. Sujeito e sociedade se constituem mutuamente, um influindo sobre o outro, numa dinâmica que impõe a condição de sujeito ativo, construtivo, em permanente interação.

Neste sentido, as ações engendradas pelo CAPS podem redirecionar a demanda e produzir novas maneiras de compreendê-la e a experienciar.

Problematizar a questão subjacente à estética negra como uma questão de Saúde Mental pode potencializar outro olhar para a vida, suas relações e reinvenção, haja vista todo o processo de socialização no contexto brasileiro que impôs um padrão estético branco como símbolo de beleza, que deforma e deprecia a imagem do negro (D’ADESKY, 2001). Como exploram Bastos e Faerstein (2012) a discriminação racial constitui uma das principais fontes de estresse, e frequentemente se combinam com outras identidades estigmatizadas, tais como classe social, escolaridade e gênero.

A demanda por alisamento de cabelo, mudança de sua textura foram reconhecidos como principal sinalizador da não aceitação de uma determinada autoimagem, que caracteriza a origem negra.

Para fazer frente a tal demanda, tanto do público feminino como masculino, as propostas giraram em torno da oferta de possibilidade de valorização do padrão blackpower, com investimento em tererês para o cabelo das mulheres, aquisição de frasco de relaxante para o cabelo crespo (carapinha), na perspectiva de redirecionar a demanda por alisamento dos cabelos, ou diversificá-la e reforço à identidade étnica, inclusive aos cabelos cacheados.

\section{Segundo Nilma Gomes}

O cabelo do negro na sociedade brasileira expressa o conflito racial vivido por negros e brancos em nosso país [...] o cabelo do negro, visto como "ruim", é expressão do racismo e da desigualdade racial que recai sobre esse sujeito. Ver o cabelo do negro como "ruim" e do branco como "bom" expressa esse conflito. Por isso, mudar o cabelo pode significar a tentativa do negro de sair do lugar da inferioridade ou a introjeção deste. Pode ainda representar um sentimento de autonomia, expresso pelas formas ousadas e criativas de usar o cabelo (GOMES, 2012, p. 3).

Confirmando tal tensionamento, houve o reconhecimento de que subjacente à demanda por alisamento de cabelo havia sofrimento, pois, após o ato concretizado, 
algumas pessoas igualmente não ficavam satisfeitas; outras até mesmo pareciam se descaracterizar, segundo a leitura do grupo, ficando como as tribos "emo". Houve, então, uma perspectiva de ações no sentido de contribuir para que a pessoa "se afirme", “assuma ser blackpower", seu "cabelo carapinha”, assumindo sua identidade étnica negra, na perspectiva de redirecionar demandas por "chapinha", por exemplo.

Tal questão, como posto, precisa realmente ser analisada a partir de cada caso, a partir da análise se há sofrimento, ambiguidades no assumir este ou aquele padrão estético. A dimensão crítica tem que estar presente, para não se reforçar novos preconceitos ou aqueles que se está querendo desconstruir, afinal, uma das vantagens dos tempos atuais é exatamente permitir a pluralidade no modo de ser, poder até mesmo construir novas identidades, se reinventar.

Obviamente, como visto, o padrão estético branco impôs-se ideologicamente, inferiorizando outros modos de ser. Mas, a partir das conquistas dos movimentos negros, a indústria cultural tem-se apropriado da estética negra e tende a valorizá-la comercialmente.

Mas os propósitos dos profissionais em empoderar e direcionar sua intervenção a partir de ações afirmativas nem sempre são bem compreendidas e aceitas pelo públicoalvo, que muitas vezes resistem a elas, como admitiu uma profissional:

- Acho que aí se vai fazendo microações afirmativas que vão fazendo eles se empoderarem da sua própria raça. A [xxx] fala do que ela se espelha, fala do cabelo duro. Ela fala do negro. Imagina! Uma vez eu vi a [nome de uma profissional] tentando falar pra ela, mas ô [nome da usuária] a sua raça, ela queria virar um bicho assim! Ela num quer. (PF)

Esta ilustração mostra o quão complexo é tratar da identidade étnica, exatamente pela questão da ideologia do embranquecimento atravessar a todos (as) os(as) brasileiros(as) igualmente, inclusive o próprio segmento negro (SOUZA, 1982). Então, lidar com questões étnico-raciais pode ser tomado como uma ofensa, uma atitude racista. Desconstruir tal imaginário constitui-se um dos desafios que não é individual, mas coletivo. 


\section{CONSIDERAÇÕES FINAIS}

Como visto, as identidades étnico-raciais necessitam ser evidenciada em Saúde Mental, até como forma de enfrentar as desigualdades sociais na distribuição dos agravos em saúde bem como o sofrimento mental.

Embora as questões da violência inerentes ao racismo tendam a se restringir à relação dual profissional x usuários, há demanda para que sejam coletivizadas, pois, ainda que incomode sobremodo os negros vitimizados, é um problema de todos, incluindo o segmento de cor branca.

A problematização das questões raciais no grupo trouxe à baila outros estereótipos e determinadas barreiras estéticas que igualmente vitimizam os trabalhadores da Saúde Mental, tais como: alguns trejeitos afeminados em algumas pessoas do sexo masculino; o corte de cabelo, curto, de uma trabalhadora, que remete alguns usuários a identificá-la com paciente oncológico; e o tamanho do seio de algumas trabalhadoras, instigadas a colocar silicone.

No geral, um profissional de Saúde Mental não espera que tal atitude preconceituosa venha de um segmento muitas vezes dupla ou multiplamente discriminado socialmente. A reação inicial da maioria dos profisssionais a esta conduta tende mesmo à indignação, revolta... mas, como informou um profissional, contam até três e tentam desfazer a cena, que tende a esgotar-se em si mesma.

Alguns invocam o contexto de crise ou não crise psiquiátrica para avaliar a violência perpetrada. A discriminação, independentemente da crise psiquiátrica, remete aos valores sociais, ao que foi incorporado ideologicamente como valor humano em uma sociedade. Mas o maior problema identificado é que a questão nunca foi pautada em reunião de equipe nem em reunião de supervisão clínico-institucional.

O silêncio é revelador da forma como a coletividade busca suprimir tal dimensão do cotidiano assistencial, por temer ferir suscetibilidades ao problematizar o "mito da igualdade racial" no interior da própria equipe, pois, como visto, a desigualdade na inserção das diferentes pessoas tem a marca da classe social conjugada às questões étnico-raciais. A inserção de parte significativa dos segmentos de baixa renda e de negros na condição de técnicos ou auxiliares de enfermagem não ocorreu naturalmente, mas é parte de um movimento histórico maior que intensificou as desigualdades sociais no contexto brasileiro, designando aos negros os postos menos valorizados socialmente. Obviamente, observa-se um movimento contrário a essa produção histórica, através da Serv. Soc. \& Saúde, Campinas, SP v. 13, n. 1 (17) p. 9-28 jan./jun. 2014 ISSN 1676-6806 
luta do movimento negro por ações afirmativas e outras estratégias que efetivamente consignem outro destino social para este segmento, consolidando, de fato, a igualdade racial.

Observou-se amiúde que os profissionais de origem branca do CAPS percebiam as investidas dos usuários sobre o segmento negro e a reação dos profissionais, no máximo, era a de se solidarizar via relações interpessoais, mas não conseguiam politizar a questão e transformá-la em questão coletiva.

Desta forma, o racismo, isto é, “[...] a atribuição de estatutos intelectuais e morais inferiores/superiores a grupos humanos/étnicos específicos" (FIGUEROA, 2004, p. 13), parece figurar como uma questão interpessoal, que fere a humanidade de todos, mas singularmente, não é tomada para fora de si, nem pelos negros, nem pelos não negros.

\section{Referências bibliográficas}

ALVES, M. C.; SEMINOTTI, N. Atenção à saúde em uma comunidade tradicional de terreiro. Revista Saúde Pública, n. 43, (Supl.1), p.85-91, 2009.

BARATA, R. B. Acesso e uso de serviços de saúde: considerações sobre os resultados da pesquisa de condições de vida 2006. São Paulo em perspectiva, São Paulo, v 22, n.2, p.19-29, julho /dez. 2008.

BARDIN, L. Análise de conteúdo. Lisboa: Edições 70, 1979.

BASTOS, J. L.; FAERSTEIN, E. Discriminação e saúde: perspectivas e métodos. Rio de Janeiro: Ed. Fiocruz, 2012.

BRASIL. Ministério da Saúde (MS). Política Nacional de saúde integral da população negra. Brasília: Ministério da Saúde, 2007.

BRASIL. Relatório final da III Conferência Nacional de Saúde Mental. Brasília: Ministério da Saúde, 2001.

BRASIL. Estatuto da Igualdade Racial. Brasília: SEPPIR/PR, 2011a.

BRASIL. Relatório final da IV Conferência Nacional de Saúde Mental Intersetorial. Brasília: Ministério da Saúde, 2011.

CAMPOS, R. O.; BACCARI, I. P. A intersubjetividade no cuidado à saúde mental: narrativas de técnicos e auxiliares de enfermagem de um Centro de Atenção Psicossocial. Ciência \& Saúde Coletiva, V 16, n.4, p.2051-2058, 2011. 
CARVALHO, M. P. O fracasso escolar de meninos e meninas: articulações entre gênero e cor/raça. In: PISCITELLI, A. et al (Org). Olhares feministas. Brasília: Ministério da Educação, 2009. p. 307-339.

CIAMPA, A. C. A estória de Severino e a história de Severina: um ensaio de psicologia social. São Paulo: Brasiliense, 1998.

COELHO FILHO, H. A Psiquiatria no país do açúcar e outros ensaios. João Pessoa: União, 1977.

CONCEIÇÃO, A. C.; NERY, G. C.; PINHO, S. R. Rubim de Pinho: fragmentos da psiquiatria transcultural. Salvador: Universidade Federal da Bahia, 2002.

D’ADESKY, J. Pluralismo étnico e multiculturalismo: racismo e anti-racismos no Brasil. Rio de Janeiro: Pallas, 2001.

FERREIRA NETO, E. História e etnia. In: CARDOSO, CFC; VAINFAS, R. (Org.). Domínios da história: ensaios de teoria e metodologia. 5.ed. Rio de Janeiro: Campus, 1997. p. 313-328.

FONSECA, E. Candomblé: a dança da vida. Recife: Massangana, 1999.

FIGUEROA, A. L. G. Contextualização conceitual e histórica. In: Anais Seminário

Nacional de Saúde da População Negra 2004. Brasília: Ministério da Saúde, 2004. p.11-45.

FREIRE, P. Pedagogia do oprimido. 17.ed. Rio de Janeiro: Paz e Terra, 1987.

FREYRE, G. Casa grande \& senzala. São Paulo: Ed. Global, 2006.

FRY, P. A persistência da raça: ensaios antropológicos sobre o Brasil e a África austral. Rio de Janeiro: Civilização Brasileira, 2005.

GIL, A.C. Métodos e técnicas de pesquisa social. 5.ed. São Paulo: Atlas, 1999.

GOMES, NL. Corpo e cabelo como símbolos da identidade negra. Rizoma, p. 641, 2012. Disponível em: <http://www.rizoma.ufsc.br/pdfs/641-of1-st1.pdf>. Acesso em:06 jul. 2012.

HELLER, A. O cotidiano e a história. Rio de Janeiro: Paz e Terra, 1989.

INSTITUTO BRASILEIRO DE GEOGRAFIA E ESTATÍSTICA - IBGE. Censo 2010. [online]. Disponível em: <http://www.ibge.gov.br/censo2010/>. Acesso em: 30 jul. 2013

LINS, F.A.D. Um retorno aos estudos de transe e doença mental nos cultos afrobrasileiros. 1992. Dissertação (Mestrado) - Centro de Filosofia e Ciências Humanas Mestrado em Antropologia, Universidade Federal de Pernambuco, Recife. 1992. 
MINAYO, M. C. O desafio do conhecimento: pesquisa qualitativa em saúde. 4.ed. São Paulo/Rio de Janeiro: Hucitec/Abrasco, 1996.

ROSA, L. C. S.; CAMPOS, R. O. Saúde mental e classe social: CAPS, um serviço de classe e interclasses. Serviço Social \& Sociedade, n. 114, p.311-331, abril /jun. 2013.

SÃO PAULO. Manual: Como e para que perguntar a cor ou raça/etnia no Sistema Único de Saúde? São Paulo: Secretaria de Estado da Saúde/Programa Estadual DST/Aids, 2009.

SARACENO, B. Manual de Saúde Mental. São Paulo: Hucitec, 1994.

SAFFIOTI, H. I. B. Gênero, patriarcado, violência. São Paulo: Fundação Perseu Abramo, 2004.

SOUZA, N.S. Tornar-se negro. Rio de Janeiro: Ed. Graal, 1982.

VIGOYA, M. V. Salud sexual y reproductiva de los varones latino americano: una lectura en clave de género, etnia y "raza". In: MINAYO, M CS; COIMBRA JUNIOR, CE. (Org.) Críticas e atuantes: Ciências Sociais e Humanas em Saúde na América latina. Rio de Janeiro: Fiocruz, 2005. p.487-501. 
Serv. Soc. \& Saúde, Campinas, SP v. 13, n. 1 (17) p. 9-28 jan./jun. 2014 ISSN 1676-6806 